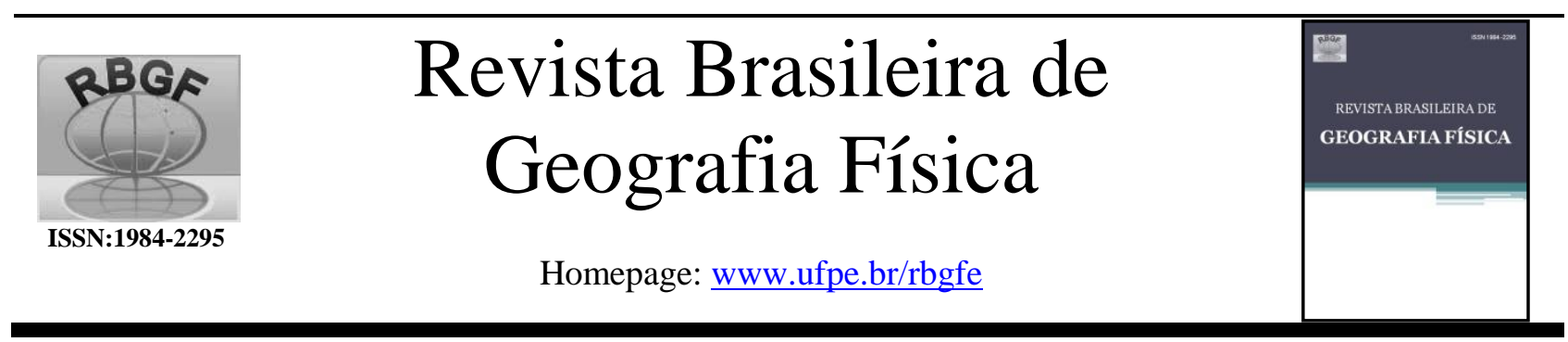

\title{
Índice de Conformidade ao Enquadramento nos Reservatórios Jucazinho, Bituri, Botafogo e Pirapama, em Pernambuco, Brasil
}

\author{
Ivanise da Silva Oliveira ${ }^{1}$, Larissa Mylena Leite Silva Panta ${ }^{2}$, Ioná Maria Beltrão Rameh Barbosa ${ }^{3}$, Simone Rosa da \\ Silva $^{4}$
}

\begin{abstract}
${ }^{1}$ Aluna do curso de Graduação em Engenharia Cartográfica e de Agrimensura na Universidade Federal de Pernambuco (UFPE). ivaniseolive@ yahoo.com.br (autor correspondente). ${ }^{2}$ Técnica em Saneamento pelo Instituto Federal de Educação, Ciência e Tecnologia de Pernambuco (IFPE). larissa.mylena97@hotmail.com. ${ }^{3}$ Professora Dra. no Instituto Federal de Educação, Ciência e Tecnologia de Pernambuco (IFPE). ionarameh@yahoo.com.br. ${ }^{4}$ Professora Dra. na Universidade de Pernambuco (UPE). simonerosa@poli.br
\end{abstract}

Artigo recebido em 24/01/2018 e aceito em 08/07/2018

\section{RES U M O}

Este artigo apresenta a aplicação do Índice de Conformidade ao Enquadramento (ICE), o qual avalia a condição de um corpo hídrico em relação às metas de enquadramento estabelecidas em reservatórios do estado de Pernambuco, correlacionando os resultados obtidos com o comportamento pluviométrico e com o uso e ocupação do solo da região na qual estão inseridos. A metodologia constituiu-se de levantamento dos dados referentes ao monitoramento sistemático da qualidade da água nos reservatórios avaliados, consulta à Resolução CONAMA n 357 de 2005 para identificação das possíveis classes de enquadramento dos corpos hídricos e cálculo do ICE. Os reservatórios apresentaram ICE em classificações distintas devido às diferenças de regime pluviométrico e de uso e ocupação do solo nas respectivas bacias de contribuição hídrica. Observou-se que os reservatórios localizados no Agreste do Estado possuem maior grau de desconformidade e estão mais distantes de atender aos objetivos do enquadramento, em comparação aos reservatórios localizados no Litoral pernambucano, que apresentam melhores condições qualitativas de água.

Palavras-chave: ICE, enquadramento, reservatórios, qualidade das águas.

\section{Guideline Compliance Index in Reservoirs Jucazinho, Bituri, Botafogo and Pirapama, in Pernambuco, Brazil}

\begin{abstract}
A B S T R A C T
This paper presents the implementation of the Guideline Compliance Index (ICE), which evaluates the condition of a water body in relation to the framework of targets in reservoirs in the state of Pernambuco, correlating the results with the rainfall behavior and with land use and occupation of the region in which they are inserted. The methodology consisted in the collection of data for the systematic monitoring of water quality in the evaluated reservoirs, studies based on the literature and based on CONAMA Resolution $n^{\circ} 357$ of 2005 to identification the framework of classes of water bodies and calculation ICE. The reservoirs showed ICE in different classifications because of differences in relation to climatic aspects and rainfall and land use and occupation of the contribution of basins in which they live, with the reservoirs located in the State of Agreste, more far from meeting the objectives of the framework compared to the reservoirs located on the Coast of Pernambuco, which showed better water conditions.
\end{abstract}

Keywords: ICE, guideline, reservoirs, water quality.

\section{Introdução}

Nas últimas décadas os corpos de água que cortam as cidades brasileiras vêm apresentando um quadro preocupante na questão da qualidade de suas águas, tendo em vista que a maioria dos municípios não conta com uma infraestrutura urbana para coleta, tratamento e destinação final dos seus resíduos e efluentes.
Conforme salienta Almeida (2014), um dos resultados desse cenário é a escassez de água com qualidade adequada, visto que as pressões antrópicas exercidas nesses meios acarretam um maior comprometimento das características desejáveis à demanda hídrica para fins de atendimento aos usos múltiplos da água. 
No que se refere à região Nordeste do país, em destaque o estado de Pernambuco, a situação é ainda mais grave. As alterações climáticas têm influenciado na irregularidade das chuvas e, consequentemente, na intensificação da escassez de água. Nessa região existem rios perenes e intermitentes, que dependem, entre outros fatores, do regime de chuvas (Alves e Freitas, 2011)

Dentro desse contexto, segundo Santos et al. (2015), a bacia hidrográfica ou suas subdivisões são consideradas como unidades de referência para a observação dos principais impactos ambientais sofridos por sua área de drenagem, visto ser ela resultado da interação entre os cursos d'água, os recursos naturais e as atividades antrópicas ali desenvolvidas. Tendo isso em vista e com o intuito de integrar qualidade e quantidade da água de forma a manter $\mathrm{o}$ bom funcionamento dos ecossistemas terrestres, a Lei $\mathrm{n}^{\circ}$ 9.433/1997 instituiu o enquadramento dos corpos hídricos como instrumento da Política Nacional de Recursos Hídricos.

$\mathrm{O}$ referido instrumento visa assegurar às águas qualidade compatível com os usos mais exigentes a que forem destinadas e diminuir os custos de combate à poluição hídrica, mediante ações diligentes. Além disso, deve-se ter como referência não somente a condição atual da qualidade da água, mas também a condição desejável de um corpo hídrico no que diz respeito ao atendimento dos usos demandados pela sociedade (ANA, 2013).

Diante deste cenário, torna-se necessário o controle quantitativo e qualitativo da água pelos órgãos gestores competentes, além da devida avaliação da qualidade da água e das possíveis influências do uso e ocupação do solo, pois, conforme destaca Ávila et al. (2016), a execução de estudos referentes aos recursos hídricos é o que produz informações capazes de fundamentar os critérios para sua gestão e tomadas de decisão.

$\mathrm{O}$ Índice de Conformidade ao Enquadramento (ICE) desenvolvido originalmente em 1997 pelo Conselho Canadense de Ministros do Meio Ambiente, tem o propósito de avaliar a condição de um corpo hídrico em relação a determinados objetivos de qualidade da água, através de um valor que sintetize as informações oriundas das variáveis de qualidade observadas, medindo a distância entre a condição atual do corpo d'água e a meta de qualidade estabelecida pelo enquadramento (CCME, 2001).

O ICE foi aplicado para rios das bacias dos rios Piracicaba, Capivari e Jundiaí por Amaro (2009), estudo este que permitiu constatar comportamento inadequado do ICE tendo como principais responsáveis poluentes com cargas orgânicas e oriundos de esgotos domésticos. Bertolin et al. (2013), após avaliação do ICE em um trecho da bacia do rio São Marcos, no estado do Rio Grande do Sul, concluiu que os resultados do ICE evidenciaram o impacto das atividades antrópicas na qualidade das águas da bacia. No contexto internacional, Lumb et al. (2006) aplicaram o Índice para estudos da qualidade da água na Mackenzie River Basin, no Canadá, estudos estes que evidenciaram o impacto da alta turbidez e metais, atribuindo-se causas naturais e antropogênicas.

Através da aplicação do ICE, o presente artigo evidenciará que a variação na qualidade da água dos reservatórios situados em Pernambuco, Jucazinho, Bituri, Botafogo e Pirapama, está relacionada à influência do regime pluviométrico e do uso e ocupação do solo da região na qual estão inseridos.

\section{Material e métodos}

\section{Área de estudo}

Segundo a Agência Pernambucana de Águas e Clima, o Plano Estadual de Recursos Hídricos - PERH (PERNAMBUCO, 1998) dividiu o Estado em 29 Unidades de Planejamento (UP), caracterizando assim, a divisão hidrográfica, composta de 13 bacias hidrográficas, 06 Grupos de Bacias de Pequenos Rios Litorâneos (GL1 a GL6), 09 Grupos de Bacias de Pequenos Rios Interiores (GI1 a GI9) e uma bacia de pequenos rios que compõem a rede de drenagem do arquipélago de Fernando de Noronha.

Foram selecionados para este estudo quatro dentre os principais reservatórios do estado de Pernambuco, os quais estão situados em unidades de planejamento hídrico diferentes e possuem comportamento climático diferenciado, conforme observado na Figura 1. Além disso, a escolha dos reservatórios implicou na maior abundância de dados que os mesmos apresentam, visto que o monitoramento não é constante para todos os reservatórios.

Os reservatórios Antônio Gouveia Neto, mais conhecido como Jucazinho e Eng. Severino Guerra, popularmente denominado Bituri, estão, respectivamente, inseridos nas bacias hidrográficas do rio Capibaribe e do rio Ipojuca no Agreste pernambucano, região essa que se caracteriza, conforme Jordão e Pereira (2010), pelo clima tropical seco e regime pluviométrico irregular, com chuvas torrenciais em determinados períodos do ano. 


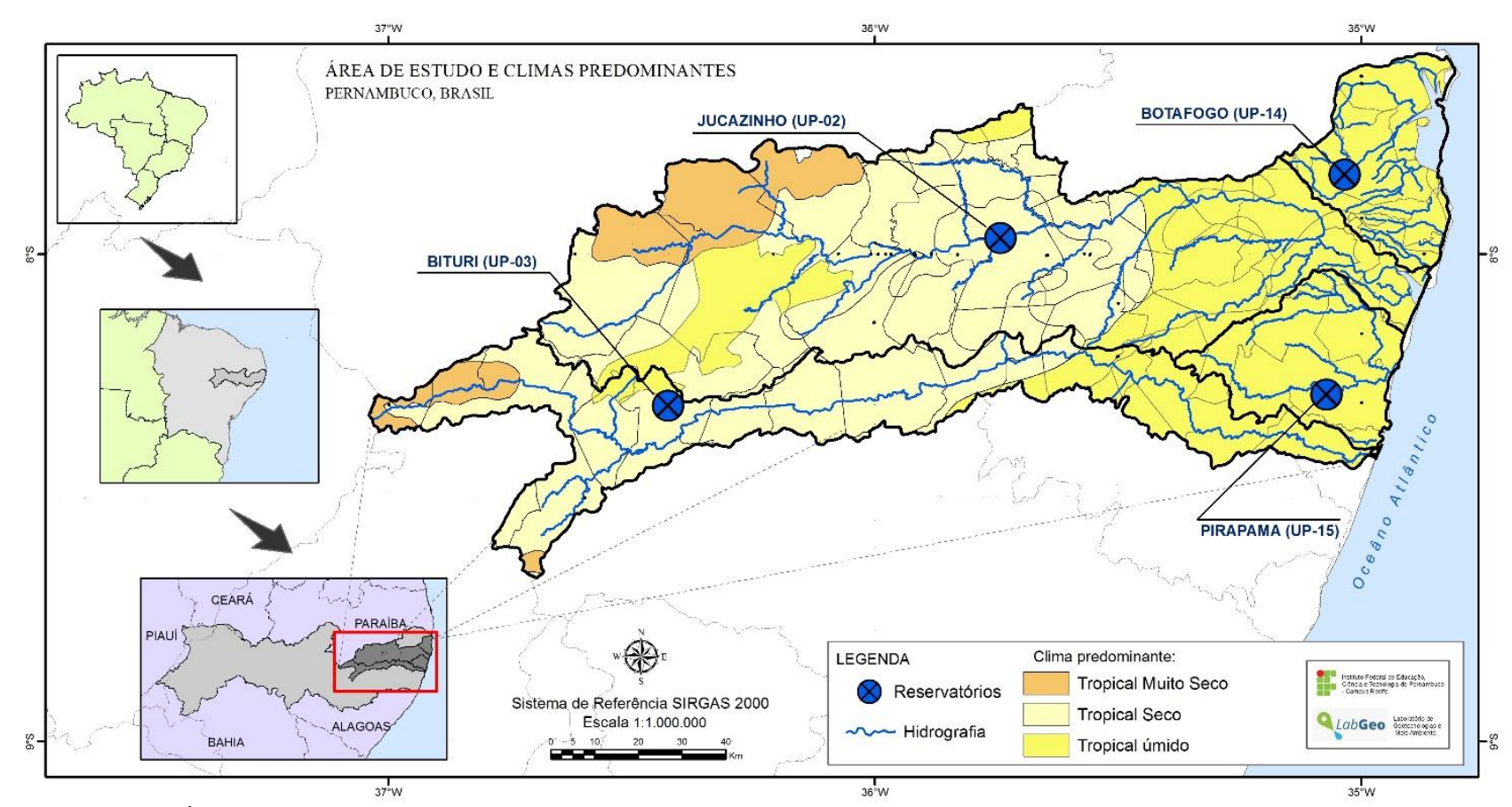

Figura 1. Área de estudo e climas predominantes.

Localizado no município de Surubim, o qual apresenta pluviometria média anual de 705,10 mm (SRHE-PE, 2010), Jucazinho possui capacidade máxima de acumulação de 327,04 milhões de metros cúbicos, sendo responsável por abastecer em torno de 800 mil habitantes da região do Agreste pernambucano. Todavia, de acordo com dados dos boletins do monitoramento dos reservatórios da Agência Pernambucana de Águas e Clima (APAC) referente a dezembro de 2017, o reservatório encontra-se seco, em situação de colapso.

O reservatório Bituri, localizado no município de Belo Jardim, o qual apresenta pluviometria média anual variando entre $650 \mathrm{~mm}$ a $1000 \mathrm{~mm}$ (CPRM, 2008), possui capacidade máxima de acumulação de 17 milhões de metros cúbicos e em dezembro de 2017, de acordo com dados da APAC, opera com 23,3\% do seu volume máximo, sendo beneficiados com suas águas cerca de 250 mil habitantes.

Os reservatórios Botafogo (Estação BF05) e Pirapama (Estação PP-53) encontram-se inseridos, respectivamente, no Grupo de Bacias Litorâneas GL2 e GL1, Região Metropolitana do Recife (RMR), ou seja, área litorânea cujo clima predominante caracteriza-se como tropical úmido e regime pluviométrico com ocorrência de chuvas distribuídas ao longo do ano (Jordão e Pereira, 2010).

Conforme dados da APAC, Botafogo, localizado no município de Igarassu, apresenta pluviometria média anual de 1634,2mm (CPRM,
2005), possui capacidade máxima de acumulação de 27,7 milhões de metros cúbicos e opera atualmente com aproximadamente $28 \%$ do seu volume máximo, abastecendo cerca de $450 \mathrm{mil}$ habitantes.

Pirapama, localizado no município do Cabo de Santo Agostinho, apresenta pluviometria média anual de 1309,9mm (CPRM, 2005) e, segundo dados do monitoramento da APAC referente a dezembro de 2017, opera com aproximadamente $95 \%$ da sua capacidade máxima de acumulação (60,9 milhões de metros cúbicos), sendo responsável por abastecer uma população de, aproximadamente, 1 milhão e 800 mil habitantes.

\section{Levantamento dos dados}

Os dados de qualidade da água para determinação do ICE foram obtidos do banco de dados do monitoramento sistemático da água realizado pela Agência Estadual de Meio Ambiente (CPRH) e pela Agência Pernambucana de Águas e Clima (APAC), no período de 2005 a 2013.

Desta maneira, foram selecionados principais parâmetros que são frequentemente monitorados para compor o cálculo do ICE, conforme apresentado na Tabela 1. 
Tabela 1. Parâmetros selecionados para composição do cálculo do ICE nos reservatórios monitorados.

\begin{tabular}{lcccc}
\hline Cianobactérias & $\mathrm{x}$ & & \\
Clorofila a & & $\mathrm{x}$ & & \\
Coliformes Termotolerantes & $\mathrm{x}$ & $\mathrm{x}$ & $\mathrm{x}$ & $\mathrm{x}$ \\
Demanda Bioquímica de Oxigênio & & $\mathrm{x}$ & $\mathrm{x}$ & $\mathrm{x}$ \\
Fósforo Total & $\mathrm{x}$ & $\mathrm{x}$ & $\mathrm{x}$ & $\mathrm{x}$ \\
Nitrogênio Amoniacal & $\mathrm{x}$ & $\mathrm{x}$ & & \\
Oxigênio Dissolvido & $\mathrm{x}$ & $\mathrm{x}$ & $\mathrm{x}$ & $\mathrm{x}$ \\
pH & $\mathrm{x}$ & $\mathrm{x}$ & $\mathrm{x}$ & $\mathrm{x}$ \\
Salinidade & $\mathrm{x}$ & $\mathrm{x}$ & $\mathrm{x}$ & $\mathrm{x}$ \\
Turbidez & & $\mathrm{x}$ & $\mathrm{x}$ & $\mathrm{x}$ \\
\hline
\end{tabular}

Vale destacar que foram desconsiderados dos cálculos os parâmetros que não possuem limites estabelecidos na Resolução CONAMA $357 / 2005$, visto que a variação da desconformidade é calculada mediante a meta estabelecida para cada classe de enquadramento dos corpos hídricos.

Também foram obtidos, através da APAC, dados históricos de volumes dos reservatórios referentes ao mesmo período analisado para verificar a relação existente entre a pluviometria e a variação da qualidade da água dos reservatórios, visto que o volume dos mesmos está diretamente relacionado ao regime de chuvas que incidem na região.

\section{Enquadramento dos reservatórios quanto à salinidade das águas}

A Resolução $n^{\circ} 357$ do Conselho Nacional de Meio Ambiente (CONAMA), de 17/03/2005, classifica as águas de acordo com seus usos preponderantes, estabelecendo limites e/ou condições para os diversos usos, dispondo sobre a classificação dos corpos de água e diretrizes ambientais para o seu enquadramento. Essa Resolução também estabelece os limites que devem ser considerados para definir as águas quanto à salinidade. Na Tabela 2 são apresentados os limites definidos para cada tipo de água.

Tabela 2. Classificação e definição das águas quanto à salinidade (CONAMA 357/2005).

CLASSIFICAÇÃo E DEFINIÇÃo

\begin{tabular}{cl}
\hline Águas doces & Salinidade igual ou inferior a \\
& $0,5 \%$ o. \\
& Salinidade superior a $0,5 \%$ e \\
& inferior a $30 \%$. $\%$. \\
& Salinidade igual ou superior a \\
Águas salinas & $30 \%$. \\
\hline
\end{tabular}

Procedeu-se o estudo da classificação dos reservatórios quanto ao enquadramento dos corpos hídricos. Para isso, inicialmente, foi analisado o teor de salinidade, a fim de identificar as águas dos corpos hídricos como doces, salinas ou salobras, observando-se os resultados do parâmetro salinidade entre os anos de 2005 e 2013, em conjunto com as finalidades de uso da água atuais dos reservatórios.

É importante destacar que este estudo não realiza o enquadramento, visto que este deve ser aprovado pelo comitê da bacia, mas, reiterando, considera as classes em função dos usos atuais da água.

\section{Cálculo do Índice de Conformidade ao Enquadramento}

$\mathrm{O}$ Índice de Conformidade ao Enquadramento é composto de três fatores: abrangência, frequência e amplitude, que criam um vetor no espaço tridimensional a partir de um método matemático de cálculo estatístico baseado na combinação desses fatores (CCME, 2001).

\section{Fator 1 - Abrangência}

Este fator representa a abrangência das desconformidades, ou seja, o número de parâmetros de qualidade da água (variáveis) que não cumprem os limites desejáveis pelo menos uma vez no período de observação. A Fórmula para o cálculo do Fator 1 é apresentada pela equação 1:

$\mathrm{F} 1=\left(\frac{\text { Número de variáveis que falharam }}{\text { Número total de variáveis }}\right) * 100$

Fator 2 - Frequência

Porcentagem de vezes que as variáveis de qualidade da água estiveram desconformes em relação ao número de observações, ou seja, os testes realizados para comparação do valor observado com o padrão definido. A fórmula para o cálculo do Fator 2 pode ser observada na Equação 2.

$\mathrm{F} 2=\left(\frac{\text { Número de testes que falharam }}{\text { Número total de testes }}\right) * 100$

Fator 3 - Amplitude

Este fator é calculado em três etapas, cuja representatividade baseia-se na quantidade pela qual o valor testado falhou, ou seja, a diferença entre o valor do parâmetro medido e o limite da classe, em conformidade com o objetivo pretendido da qualidade da água, calculando-se através de três etapas: 
O número de vezes em que a concentração da variável observada é maior que o limite estabelecido (ou menor que, quando o objetivo desejado é um valor mínimo).

O número de vezes que os testes realizados estão em desacordo com o limite legal estabelecido; sendo calculado através da soma de todas as variações individuais dos testes desconformes, dividida pelo número total de testes, sendo denominada pela soma normatizada das variações, ou snv.

O valor desta etapa é calculado através da snv em relação aos limites estabelecidos, com valores reduzidos a uma variável entre 0 e 100 . Para isso, é utilizado o valor 1,732, a fim de garantir o comprimento máximo do vetor que representará a desconformidade.

$$
\mathrm{F} 3=\frac{\mathrm{snv}}{0.01 \mathrm{snv}+0.001}
$$

A partir dos fatores calcula-se o ICE, de acordo com a equação 4.

$\mathrm{ICE}=100-\left(\frac{\sqrt{\mathrm{F}^{2}+\mathrm{F} 2^{2}+\mathrm{F}^{2}}}{1,732}\right)$

Os valores do ICE são classificados em cinco categoriais, conforme, conforme Tabela 3.

Tabela 3. Classificação do ICE conforme (CCME,2001).

\begin{tabular}{|c|c|}
\hline \multicolumn{2}{|c|}{ CLASSIFICAÇÃO E DESCRIÇÃO DO ICE } \\
\hline $\begin{array}{l}\text { Excelente } \\
(95-100)\end{array}$ & $\begin{array}{l}\text { A qualidade da água é protegida e a } \\
\text { condição do corpo hídrico está } \\
\text { muito próxima aos níveis naturais. }\end{array}$ \\
\hline $\begin{array}{c}\text { Bom } \\
(80-94)\end{array}$ & $\begin{array}{l}\text { A qualidade da água é protegida, } \\
\text { apresentando apenas pequeno grau } \\
\text { de impacto. }\end{array}$ \\
\hline $\begin{array}{l}\text { Mediano } \\
(65-79)\end{array}$ & $\begin{array}{l}\text { A qualidade da água é geralmente } \\
\text { protegida, no nontanto } \\
\text { ocasionalmente é ameaçada ou } \\
\text { danificada. }\end{array}$ \\
\hline $\begin{array}{l}\text { Marginal } \\
(45-64)\end{array}$ & $\begin{array}{l}\text { A qualidade da água é } \\
\text { frequentemente danificada ou } \\
\text { ameaçada. }\end{array}$ \\
\hline $\begin{array}{l}\text { Ruim } \\
(0-44)\end{array}$ & $\begin{array}{l}\text { A qualidade da água quase sempre é } \\
\text { danificada ou ameaçada. }\end{array}$ \\
\hline
\end{tabular}

Para cálculo do ICE foram elaboradas planilhas em Microsoft Excel @ com os resultados dos parâmetros do monitoramento sistemático da qualidade da água para cada reservatório em estudo.

\section{Resultados e discussão}

As águas do reservatório Jucazinho são definidas como águas salobras, baseando-se no valor da salinidade observado nos anos de 2005 a 2013. Neste período, das 50 amostras de água coletadas através do monitoramento, todas apresentaram-se com valores de salinidade maior que $0,5 \%$ e inferior a $30 \%$.

As águas dos reservatórios Bituri, Botafogo e Pirapama são definidas como doce, baseando-se no valor da salinidade observada no mesmo período (2005 a 2013). Neste período, para Bituri, Botafogo e Pirapama, respectivamente, das 18,48 e 47 amostras de água coletadas, em períodos trimestrais, todas se apresentaram com valores de salinidade inferior a $0,5 \%$.

Por outro lado, os corpos hídricos do estado de Pernambuco ainda não foram enquadrados segundo a CONAMA 357/05 e diante da necessidade de fazer comparação dos resultados das análises com os limites máximos e mínimos de alguns parâmetros estabelecidos na legislação, procedeu-se um levantamento dos usos da água existentes nos reservatórios em estudo, buscandose identificar possíveis classes de água salobra e de água doce.

Verificou-se que as águas do Jucazinho poderiam se enquadrara Classe 1 - Salobra, por, atualmente, ser destinada à recreação de contato primário, à proteção das comunidades aquáticas, à aquicultura e à atividade de pesca, ao abastecimento para consumo humano após tratamento convencional ou avançado e à irrigação de hortaliças e de frutas.

Além disso, observou-se que, segundo a Resolução CONAMA 357/2005, enquanto não forem aprovados os respectivos Enquadramentos, as águas doces serão consideradas Classe 2, as salinas e salobras devem ser consideradas Classe 1, exceto se as condições de qualidade atuais forem melhores, o que determinará a aplicação da classe mais rigorosa correspondente, ratificando as classes ora identificadas.

Diante disso, as águas dos reservatórios Bituri, Botafogo e Pirapama são consideradas Classe 2 - Doce. As águas do reservatório Bituri são destinadas ao abastecimento para consumo humano, após tratamento convencional, a proteção das comunidades aquáticas, a irrigação de hortaliças e de plantas frutíferas e a aquicultura. Os reservatórios de Botafogo e Pirapama são utilizados, atualmente, para fins de abastecimento público, após tratamento convencional.

Os resultados obtidos do ICE dos reservatórios em estudo, no período de verificação 
entre os anos 2005 e 2013, são apresentados nas figuras 2 e 3 , nas quais são considerados os resultados numéricos do índice e sua correlação com os aspectos de volume anual acumulado nas barragens monitoradas.

Os gráficos permitiram a visualização da evolução temporal do ICE para avaliação da condição dos corpos hídricos em relação à classe de enquadramento junto à análise da situação pluviométrica anual, de acordo com o volume de água acumulado. Além disso, os mapas temáticos facilitaram a correlação dos resultados com os aspectos de uso e ocupação do solo nas respectivas bacias de contribuição.
Para apresentação dos resultados, os reservatórios foram agrupados em dois grupos diferentes, o primeiro para os mananciais inseridos no Agreste de Pernambuco e o segundo com os que estão localizados no Litoral Pernambucano.

\section{Reservatórios do Agreste}

A Figura 2 apresenta os resultados do ICE aplicado aos reservatórios Jucazinho e Bituri. No gráfico é apresentado, em uma única escala de valores, as variáveis do ICE (0 a 100) e do volume acumulado em metros cúbicos.

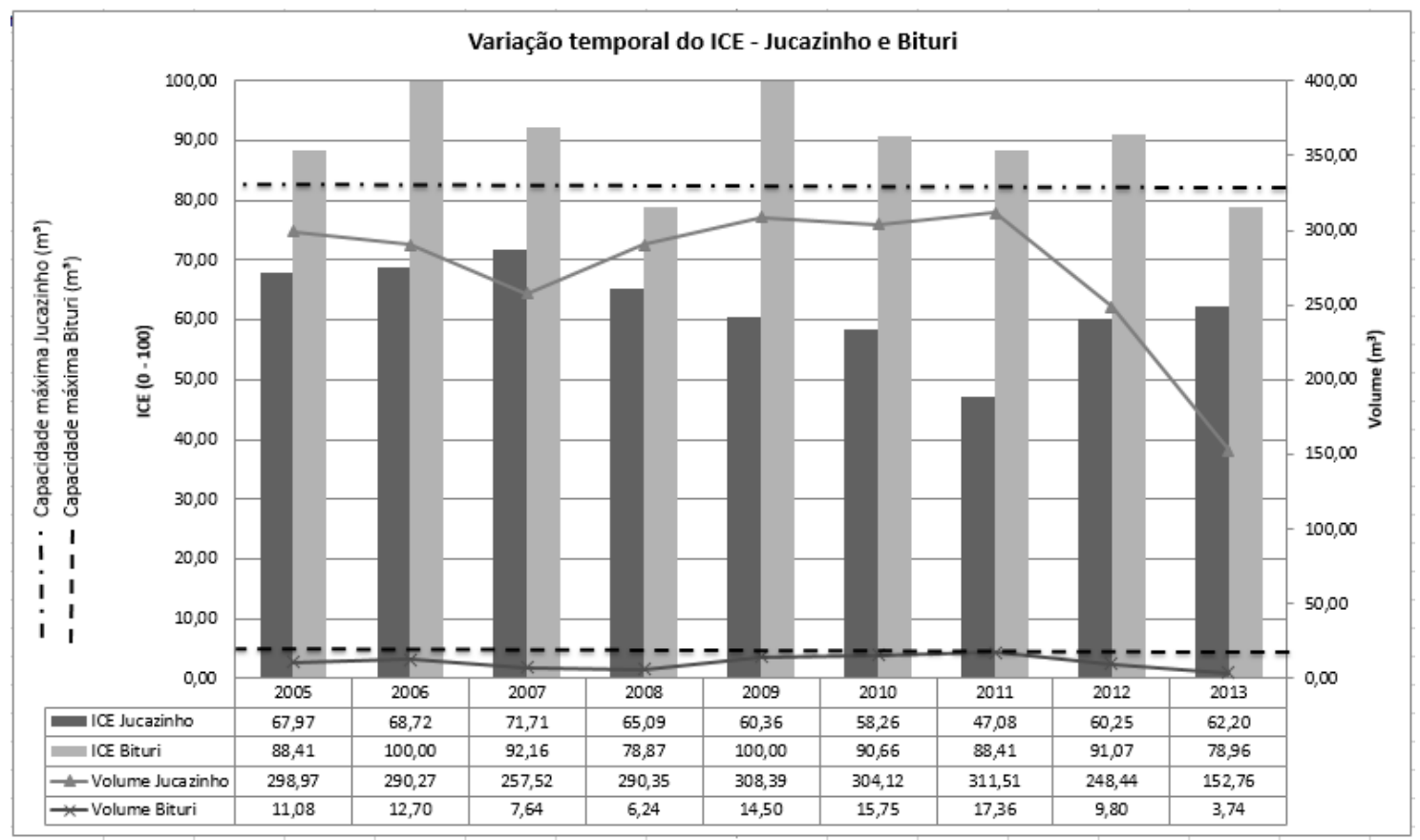

Figura 2 - Gráfico da variação temporal do ICE e volumes armazenados entre 2005 e 2013 para os reservatórios Jucazinho e Bituri.

A aplicação do ICE para os reservatórios do Agreste constatou comportamento, no geral, de desconformidade aos parâmetros estabelecidos. Observa-se que, de acordo com a Figura 2, o reservatório Jucazinho, em comparação ao Bituri, apresenta maiores desconformidades quanto aos valores do ICE e, desta forma, esteve mais distante de atender as metas do enquadramento.

Quanto ao reservatório Jucazinho, o ano de 2011 destacou-se pelo elevado aporte de Fósforo Total em relação aos outros anos, o qual chegou a um valor aproximadamente doze vezes maior que o limite máximo aceitável para a classe de enquadramento correspondente; eventos esses que afetaram negativamente o fator 3 do ICE, que representa a amplitude da desconformidade, contribuindo, assim, para o decaimento da qualidade das águas e, consequentemente, para a piora do ICE.

Além disso, foi possível constatar que, de acordo com o volume acumulado nos reservatórios ao longo do tempo, para o reservatório Jucazinho, a pluviometria atua negativamente na piora das condições hídricas. Este comportamento pode ser explicado pelo aumento do processo de lixiviação, pois, conforme salienta Barbosa e Cirilo (2015), o rio Capibaribe, mais especificamente o trecho a montante deste reservatório, é destino de esgotos domésticos dos núcleos urbanos de Santa Cruz do Capibaribe e Toritama, bem como dos efluentes 
industriais de lavanderias de jeans neste último município, que chegam ao rio sem o tratamento adequado.

Ainda conforme Barbosa e Cirilo (2015), devido às baixas vazões verificadas no rio Capibaribe, à montante do Jucazinho, verifica-se estagnação das águas e pouco transporte de sedimentos. Sendo assim, no período de chuvas torrenciais, as substâncias, provenientes dos efluentes lançados ao rio durante todo o ano, chegam ao reservatório.

Em estudo dos impactos das alterações de uso e ocupação do solo considerando a variabilidade climática e hidrológica na região do semiárido, Siqueira et. al (2017) constatou que, para os dados de escoamento superficial e produção de sedimentos, pode-se verificar que a redução da precipitação implica em uma redução desses processos.

Portanto, é possível notar uma tendência a melhora do ICE à medida que o volume do reservatório Jucazinho diminui.

Todavia, para o reservatório Bituri constatou-se uma tendência a melhora do ICE à medida que o seu volume aumenta. Isso pode estar ocorrendo devido à ação diluidora da chuva aliado aos fatores morfométricos, como a forma e a topografia, da bacia hidrográfica do Ipojuca que facilitam o escoamento das águas das chuvas.

Além disso, Aragão (2011) em estudo da distribuição e quantificação e populações e cianobactérias em reservatórios do estado e Pernambuco, constatou Bituri entre os reservatórios no qual registraram-se as menores densidades totais de cianobactérias, fato pelo qual reitera a possível melhora o ICE, visto que este parâmetro foi incluído no cálculo do ICE para Bituri.

\section{Reservatórios do Litoral}

A Figura 3 apresenta os resultados do ICE aplicados aos reservatórios Botafogo e Pirapama. No gráfico também é apresentado, em uma única escala de valores, as variáveis do ICE (0 a 100) e do volume acumulado em metros cúbicos.

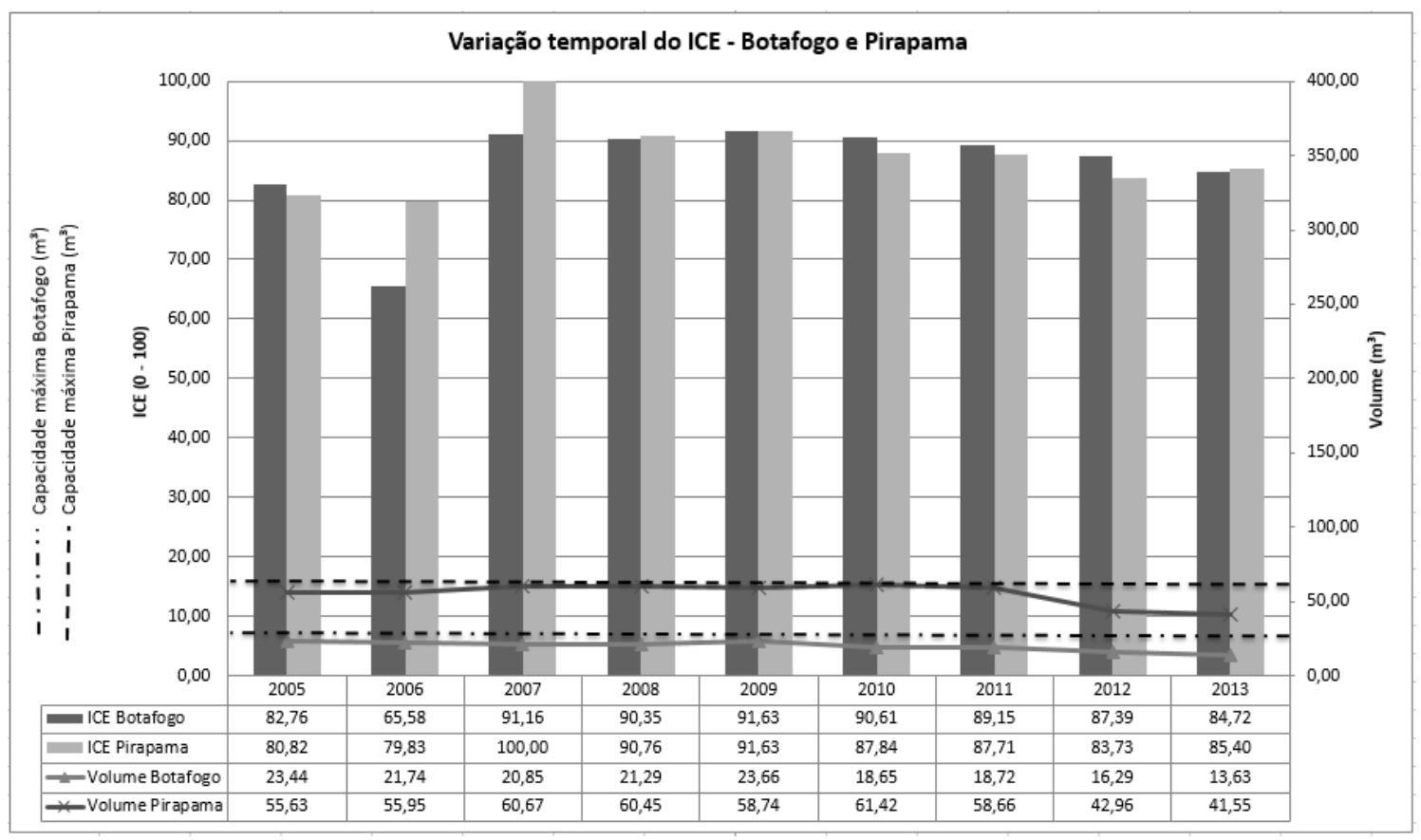

Figura 3 - Gráfico da variação temporal do ICE e volumes armazenados entre 2005 e 2013 para os reservatórios Botafogo e Pirapama.

De acordo com os resultados do ICE, constata-se que, de um modo geral, as águas dos reservatórios Botafogo e Pirapama encontram-se próximos à classe 2, atribuídas a esses reservatórios.

Observa-se, no ano de 2006, os resultados mais distantes do desejável, sendo classificado como mediano tanto para o reservatório Botafogo, quanto para o Pirapama. Esta classificação pode ser atribuída a contribuição do parâmetro Fósforo Total, que apresentou, neste ano, concentrações de aproximadamente dez vezes maior, para Pirapama, e cinquenta vezes, para Botafogo, que o limite máximo aceitável, o que contribuiu para a piora do ICE. 
Apesar da classificação em 2006, os valores do ICE para Botafogo e Pirapama não são considerados significativos quanto à piora da qualidade hídrica quando comparados aos valores apresentados pelos reservatórios inseridos no Agreste.

Conforme observa-se na Figura 3, a pluviometria, neste caso representado pelo volume do reservatório, é fator determinante para a melhora do ICE, pois à medida que há incidência de chuvas, o valor do ICE aumenta e melhora sua classificação. De igual forma ocorreu no rio Atibaia em São Paulo, de acordo com Amaro (2009) quanto maior é o volume, maior é a diluição dos contaminantes, oriundos das fontes poluidoras da bacia, consequentemente o ICE é favorecido.

Com exceção de 2006, em ambos os reservatórios, todos os anos apresentaram resultados favoráveis quanto à proximidade de atendimento ao enquadramento. Nesse sentido, a pluviometria na RMR, que se apresenta com maior frequência e menor intensidade que no Agreste, favorece a diluição dos nutrientes nos reservatórios.

\section{Influências antrópicas nas bacias hidrográficas dos reservatórios}

Diante dos resultados obtidos para o ICE, a análise do uso do solo permitiu pontuar possíveis influências antrópicas que se correlacionam com os resultados apresentados pelos reservatórios.

Conforme a Figura 4, no entorno o reservatório Jucazinho, observa-se a presença de campos antrópicos e núcleos urbanos, o que pode justificar os baixos valores do ICE para esse reservatório. Os núcleos urbanos que margeiam o rio Capibaribe não possuem sistema de esgotamento sanitário e lançam seus esgotos nas galerias de águas pluviais ou diretamente no rio. Outro fato que agrava o problema de qualidade hídrica do Jucazinho é que, desde 2004, não é efetuada a descarga de fundo no manancial, o que contribui ainda mais para o acúmulo de nutrientes no manancial.

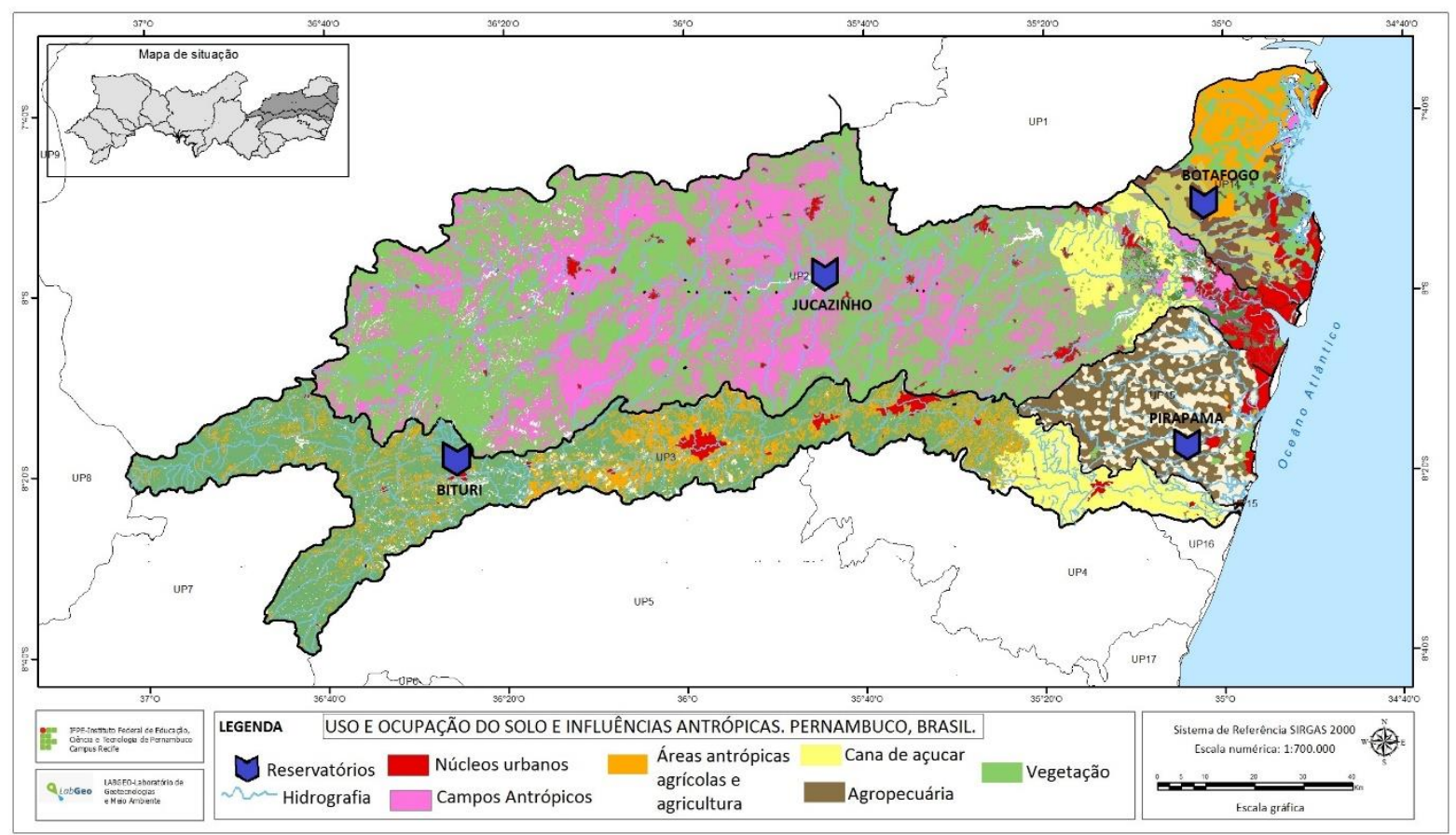

Figura 4 - Mapa de uso e ocupação do solo e influencias antrópicas nas áreas em estudo.

Fonte: produzido de acordo com dados da Secretaria de Recursos Hídricos e Energéticos de Pernambuco.

Martins (2017) aponta que áreas antropizadas são caracterizadas pela presença de atividades potencialmente poluidoras, assim, tendo em vista que nas proximidades do

reservatório Bituri nota-se a presença de áreas antrópicas agrícolas e alguns núcleos urbanos, os impactos à qualidade de suas águas tornam-se significativos.

No entanto, para os reservatórios Botafogo e Pirapama, não se verificam núcleos urbanos muito próximos, que possam contribuir com o lançamento de efluentes. Observa-se, porém, áreas destinadas a agropecuária, que, de certa forma, também podem vir a contribuir para a poluição desses mananciais. 
Conforme Oliveira (2015), os diversos tipos de uso na bacia podem comprometer a qualidade de água do reservatório, por contaminação e pelo assoreamento, estando esses relacionados ao escoamento superficial que transporta sedimentos, nutrientes lixiviados e outros contaminantes.

\section{Conclusões}

Conforme os resultados obtidos, a aplicação do ICE permitiu comprovar a relação existente entre a variação da qualidade da água e a influência do regime pluviométrico que ora atua positivamente e ora negativamente, a depender, principalmente, do fator uso e ocupação do solo na região na qual os reservatórios estudados inseremse e dinâmica das bacias de contribuição.

Quanto aos reservatórios do Agreste, para Jucazinho a piora da qualidade da água esteve aliada à concentração de poluentes, favorecida pelo período chuvoso. No entanto para Bituri, a pluviometria atuou na diluição dos poluentes e na melhoria das condições hídricas. Assim como, semelhanças apresentadas entre os reservatórios inseridos no Litoral, permitiram a melhoria das condições de qualidade da água, pela maior frequência e menor intensidade de chuvas. Os resultados do ICE constatam, então, a necessidade de maior atenção para corpos hídricos pernambucanos mais expostos a influências antrópicas, assim como a condições adversas quanto à regularidade de chuvas.

Desta forma, a avaliação do comportamento dos reservatórios ao longo do tempo em relação a sua condição hídrica de atendimento ao enquadramento através do ICE, reafirma a importância do acompanhamento periódico dos corpos hídricos por meio de dados consistentes e das condições locais de uso do solo e, sendo assim, permitindo elencar prioridades de investimentos em políticas públicas de melhoria em infraestrutura e saneamento solo. Isso se faz necessário, principalmente, quando esses reservatórios são destinados aos usos mais nobres, como o abastecimento humano.

\section{Agradecimentos}

Os autores agradecem ao PIBIC-IFPE pelo apoio financeiro, bem como à APAC-CPRH por conceder dados imprescindíveis à realização da pesquisa.

\section{Referências}

Almeida; G. S, 2014. Avaliação da aplicação do IQA-CCME na divulgação da qualidade de água de bacias hidrográficas. Estudo de caso: bacia hidrográfica do rio Joanes. Dissertação (Mestrado). Salvador, UFBA.

Alves, A.M., Freitas, R., 2011. Bacias Hidrográficas: estudo regional de ações estruturadoras na unidade de planejamento hídrico do rio Ipojuca, 1.ed. CONDEPE/FIDEM, Recife.

Amaro, C. A., 2009. Proposta de um índice para avaliação de conformidade da qualidade dos corpos hídricos ao enquadramento. Dissertação (Mestrado). São Paulo, Poli-USP.

ANA. Agência Nacional de Águas, 2013. Conjuntura dos recursos hídricos no Brasil. Brasília.

Aragão, N.K.C.V., 2011. Taxonomia, distribuição e quantificação de populações de cianobactérias em reservatórios do estado de Pernambuco (Nordeste do Brasil). Dissertação (Mestrado). Recife, UFRPE.

Ávila, M.W., Hora, M.A.G.M., Ávila, C.R., Alves, F.V., Faria, M.M., Vieira, M.R., 2016. Gestão qualitativa dos recursos hídricos. Proposta metodológica para o planejamento de uma rede de estações de monitoramento da qualidade de águas superficiais. Estudo de caso: bacia hidrográfica do Rio Muriaé. Revista Brasileira de Recursos Hídricos [online]. Disponível: http://dx.doi.org/10.21168/rbrh.v21n2.p401415. Acesso: 04 jun. 2018.

Barbosa, I..B.R., Cirilo, J.A., 2015. Contribuição média de fósforo em reservatório de abastecimento de água. Eng. Sanitária e Ambiental, V. 20, n.1 39-46. http://dx.doi.org/10.1590/S141341522015020000098008.

Bortolin, T.A., Guerra, G.S., Peresin, D., Mendes, L.A., Schneider, V. E., 2013. Avaliação do índice de conformidade ao enquadramento em um trecho da bacia do rio São Marcos. XX Simpósio Brasileiro de Recursos Hídricos. Disponível: https://abrh.s3.sa-east1.amazonaws.com/Sumarios/155/1b7a5c287 349bf540536603497a61983_dd75e59705799 455d2f6f7ff4b071c98.pdf. Acesso: 20 jan. 2018.

BRASIL, 1997. Lei $\mathrm{n}^{\circ} 9433$, de 8 de janeiro.

CCME. Canadian Council of Ministers of the Environment, 2001. Canadian Water Quality Guidelines for the Protection of Aquatic Life. 
CCME Water Quality Index 1.0 User's Manual. Winnipeg.

CONAMA, 2005. Resolução 357, de 17 de março.

CPRM. Serviço Geológico do Brasil, 2005. Projeto cadastro de fontes de abastecimento por água subterrânea Pernambuco, diagnóstico do município de Igarassu. Recife.

CPRM. Serviço Geológico do Brasil, 2005. Projeto cadastro de fontes de abastecimento por água subterrânea Pernambuco, diagnóstico do município de Cabo de Santo Agostinho. Recife.

CPRM. Serviço Geológico do Brasil, 2008. Geologia da Folha Belo Jardim. Brasília.

Jordão, F., Pereira, R. R., 2010. Água para o Agreste, 1 ed. Editora Manifesto, Belo Horizonte.

Lumb, A., Halliwell, D., Sharma, T., 2006. Appication of CCME Water Quality Index to Monitor Water Quality: a case of the Mackenzie River Basin, Canada. Environmental Monitoring and Assessment. Disponível: https://www.environmentalexpert.com/Files/6063/articles/8597/1.pdf. Acesso: 14 set. 2017.

Martins, I. A., 2017. Modelagem em SIG da fragilidade ambiental para o processo de eutrofização antrópica em reservatórios tropicais. Tese (Doutorado). São Paulo, USP.

Oliveira, M. A. M., 2017. Mensuração de perdas de sedimentos por escoamento superficial em encostas, com uso de parcelas de erosão, em diferentes usos e coberturas do solo no Bioma Cerrado: Bacia Hidrográfica do Ribeirão do Gama/DF. Dissertação (Mestrado). Brasília, UnB.

PERNAMBUCO. Secretaria de Recursos Hídricos, 1998. Plano Estadual de Recursos Hídricos: documento síntese. Recife.

Santos, K.P., Kopp, K., Oliveira, W.N., 2015. Métodos de avaliação rápida da integridade ambiental aplicados à Bacia do Ribeirão Sozinha, Goiás. Revista Brasileira de Recursos Hídricos [online]. Disponível: https://www.abrh.org.br/SGCv3/index.php?P $\mathrm{UB}=1 \& \mathrm{ID}=157 \& \mathrm{SUMARIO}=5071$. Acesso: 22 mai. 2018

Siqueira, M.S., Alcântara, H.M., Ribeiro, G.N., Medeiros, P.C., Afonso, J.S.D., Medeiros, A.C., Maracajá, P.B., 2017. Impactos das alterações de uso e ocupação do solo considerando a variabilidade climática e hidrológica da região do semiárido. Revista Brasileira de Gestão Ambiental. Disponível: http://www.gvaa.com.br/revista/index.php/R BGA/index. Acesso: 05 mai. 2018.

SRHE-PE. Secretaria de Recursos Hídricos e Energéticos, 2010. Plano Hidroambiental da Bacia do Rio Capibaribe, Recife. 